Obere Extremität 2018 $\cdot 13: 112-120$ https://doi.org/10.1007/s11678-018-0456-2 Received: 24 December 2017

Accepted: 16 April 2018

Published online: 15 May 2018

(c) The Author(s) 2018

\section{CrossMark}

\author{
R. Nietschke ${ }^{1}$ (iD $\cdot$ K. J. Burkhart ${ }^{1}$ B. Hollinger ${ }^{1}$ F. I. Dehlinger ${ }^{3} \cdot$ A. Zimmerer ${ }^{1} \cdot$ \\ M. M. Schneider ${ }^{1,2}$ \\ ' Upper Extremity Unit, ARCUS Sportklinik, Pforzheim, Germany \\ ${ }^{2}$ University Witten/Herdecke, Witten, Germany \\ ${ }^{3}$ ACURA Kliniken, Albstadt, Germany
}

\title{
Reasons for surgical revision after conservatively treated radial head fractures-retrospective study of 70 patients
}

developed a symptomatic hypertrophic plica [6]. The authors concluded that the trauma mechanism is nearly the same as in elbow dislocations. In some cases, there was evidence on magnetic resonance imaging (MRI) or intraoperative findings that the Mason I fracture was actually a Mason IV fracture. In addition, Davidson et al. demonstrated, as part of stress tests with radial head fractures, that all fractures had instabilities due to either valgus or axial stress [9]. Itamura et al. emphasized that only $12.5 \%$ of the radial head fractures in their case series did not have any relevant ligament injuries [19].

In the case of Mason II fractures, good results are achieved by conservative and operative measurements alike $[2,10,15$, $18,28]$.

Lindenhovius and coworkers did not find better clinical long-term results following operative treatment of Mason II fractures in comparison with the longterm results of nonoperative management published by Akesson et al. [2, 28]. The high rate of posttraumatic arthritis in the nonoperative group in the latter study is noteworthy. Although the authors state that these cases are asymptomatic, we believe this to be a worrisome aspect of the conservative treatment of displaced radial head fractures as radiocapitellar arthritis is known to be one of the most challenging problems in elbow surgery-especially in the young and active patient. Therefore, the present study evaluates and describes the sequelae of failed conservative treatment after radial head fractures.

\section{Patients and methods}

\section{Patients}

This retrospective, descriptive, and explorative observational study included patients who underwent surgery for fracture sequelae after conservatively treated radial head fractures. We identified 70 patients ( 28 women and 42 men) treated between 2007 and 2016. Initial treatment was conducted outside our hospital. Patients were referred to our elbow center after their initial presentation elsewhere. The average age of the patients was 41.83 years (range, 16-75 years). There were 40 right and 30 left elbows affected.

On average, the duration of conservative therapy was 50 months (range, 5-360 months) from the time of trauma to surgery.

The study included all patients who underwent conservative treatment for at least 5 months or longer. We also included eight patients (11.4\%) who had previous surgeries, e.g., arthrolysis, elsewhere.

\section{Arthroscopy}

The procedure for arthroscopy is described here. We created five standard working portals: anteroradial, antero- 

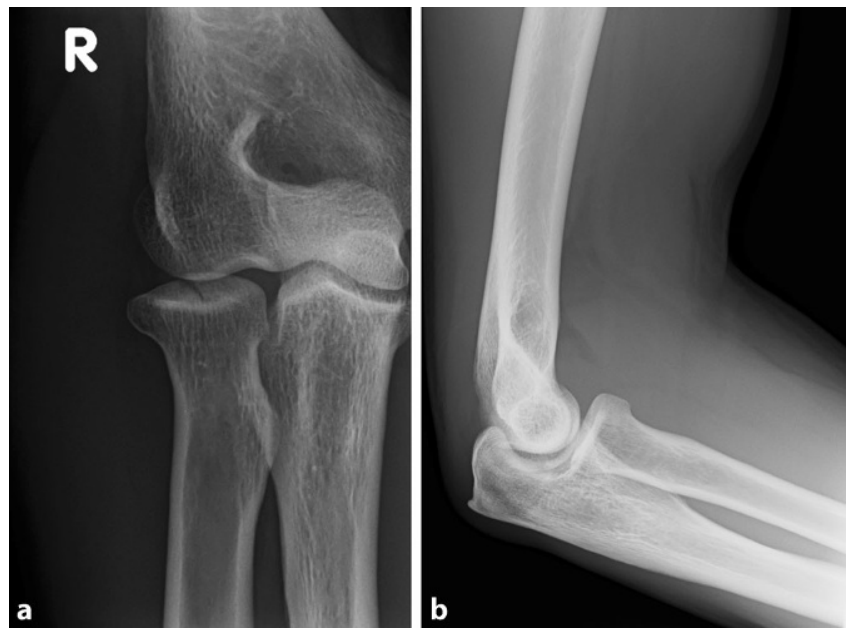

Fig. $1 \triangleleft$ Radiographs (two planes) of a radial head fracture (Mason I)
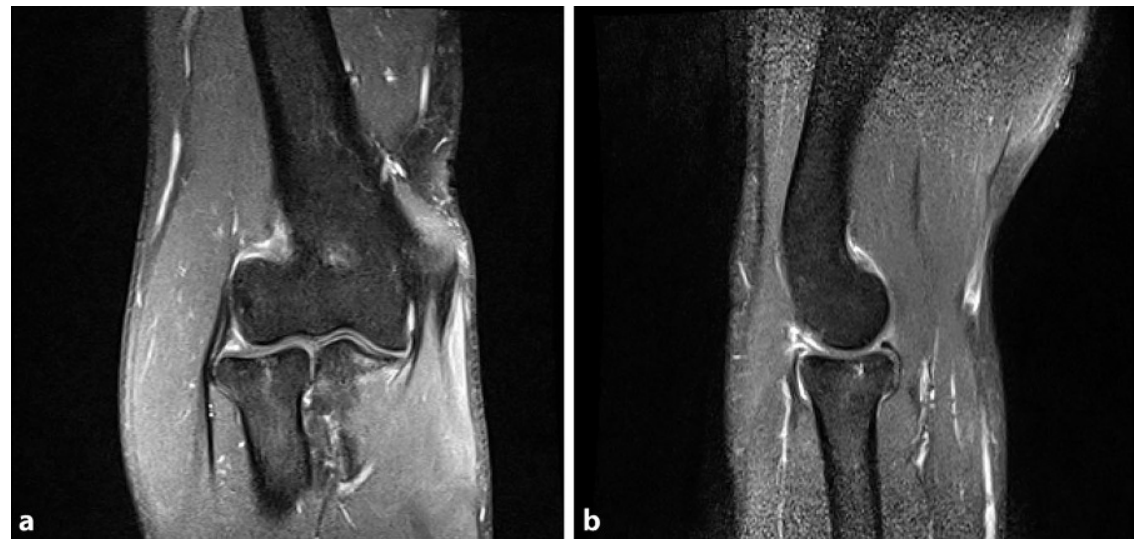

Fig. 2 A Magnetic resonance imaging of Mason I radial head fracture and absence of soft tissue damage
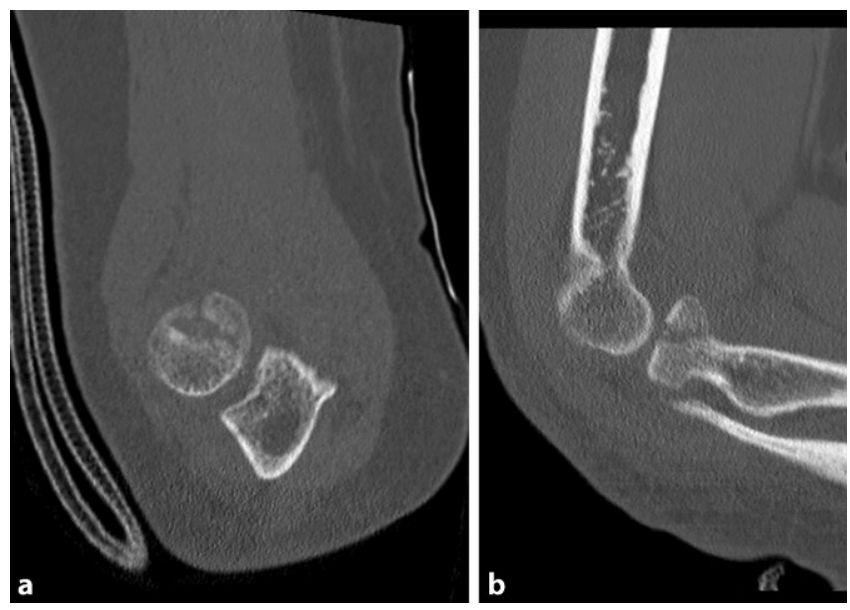

Fig. $3<$ Computed tomography scans of a radial head fracture (Mason II)

ulnar, trans-tricipital, proximal dorsoradial, and distal dorsoradial.

After joint insufflation through the soft spot portal with $20 \mathrm{ml}$ of normal saline solution, an inflow cannula was placed for the continuous supply of arthroscopy fluid via the anteroradial
Finally, we used the deep dorsoradial portal as an access to test the stability with an exchange rod inserted into the ulnohumeral joint.

We distinguished between three degrees of instability, according to the classification of O'Driscoll et al. [38]:

- Grade I: subluxation (posterolateral rotatory instability, PLRI)

- Grade II: incomplete dislocation (PLRI II)

- Grade III: complete dislocation (PLRI III)

The anterior joint compartment was examined by using the anterolateral portal. If necessary, arthroscopic cartilage debridement, micro-fracturing, synovectomy, and/or capsulectomy was carried out after creating an antero-ulnar portal.

Medical files were analyzed according to the fracture sequelae, range of motion, stability, and patient complaints. Each of our patients was re-evaluated 6 weeks postoperatively. Patient data were collected retrospectively and postoperative evaluation was completed with the help of the available medical history. No telephone interview or personal examination was performed in this study.

\section{Results}

In 35 cases (50.0\%), retrospective grading according to the Mason classification could not be made because radiological images at the time of the trauma were absent and there was incomplete or missing data on the initial classification. In the remaining 35 patients, there were 20 type I, eight type II, five type III, and two type IV fractures.

Approximately half of our patients (55.7\%) were immediately immobilized with a plaster after trauma. The duration of the immobilization was 3.4 weeks (range, 1-8 weeks) on average. Five patients $(7.1 \%)$ were treated with orthopedic devices after trauma (e.g., hinged external fixator, etc.).

In all, $98.6 \%$ of patients complained of pain in the affected elbow; only one patient specified no pain. 
Obere Extremität 2018 · 13:112-120 https://doi.org/10.1007/s11678-018-0456-2

(c) The Author(s) 2018

R. Nietschke · K. J. Burkhart · B. Hollinger · F. I. Dehlinger · A. Zimmerer $\cdot$ M. M. Schneider

\section{Reasons for surgical revision after conservatively treated radial head fractures—retrospective study of 70 patients}

\section{Abstract}

Background. An inadequate clinical outcome after conservatively treated radial head fractures is not uncommon. We analyzed the subjective limitations, objective complaints, and surgical procedures for radial head fractures initially treated conservatively. Patients and method. Between 2007 and 2016, 70 patients ( 42 men, 28 women) who suffered from fracture sequelae after conservatively treated radial head fractures were examined. Demographic (age, 41.8 years, range, $16-75$ years) and clinical data (pain, range of motion, instability) were retrospectively evaluated.

Results. The average time to surgery after trauma was 50 months (range, 5-360 months).
In 38 cases, radial head fractures were initially treated with immobilization for 3.4 weeks (range, 1-8 weeks). Physiotherapeutic treatment was performed in 39 cases. In only half of the cases was retrospective Mason classification possible: 20 type I, 8 type II, 5 type III, and 2 type IV. Of the 70 patients, 53 had posttraumatic elbow stiffness; 34 had isolated lateral and four patients isolated medial ligament instability. There were eight cases with a combination of lateral and medial ligament instability and 27 cases of elbow stiffness combined with instability. An average of 1.2 (range, 1-4) surgical procedures per patient were performed. In all, 64 patients underwent elbow arthroscopy with arthrolysis and additional treatment depending on other injuries. The range of motion improved on average from preoperative flexion/extension of $131-15-0^{\circ}$ to postoperative flexion/extension of $135-5-0^{\circ}$ (gain in flexion: $4.2^{\circ}$ and extension: $10.6^{\circ}$.

Conclusion. Conservative treatment of radial head fractures does not always yield good results. Reasons for a poor outcome include chronic instability, cartilage damage, stiffness, or a combination thereof. Improved outcomes can be achieved via arthroscopic arthrolysis.

Keywords

Radius fractures · Elbow · Joint instability . Osteoarthritis · Surgery

\section{Revisionsgründe nach konservativ behandelten Radiuskopffrakturen - Retrospektive Analyse von 70 Patienten}

\section{Zusammenfassung}

Hintergrund. Patienten mit unzureichendem klinischem Ergebnis nach konservativ behandelten Radiuskopffrakturen sind nicht selten. Ziel der vorliegenden Studie war eine Analyse von subjektiven Einschränkungen, objektiven Beschwerden und chirurgischen Eingriffen nach anfänglich konservativ behandelten Radiuskopffrakturen.

Patienten und Methode. Zwischen 2007 und 2016 wurden 70 Patienten (42 Männer, 28 Frauen) untersucht, die an Frakturfolgen nach konservativ behandelten Radiuskopffrakturen litten. Demographische (Alter im Mittel: 41,8 Jahre; Spanne: 16-75 Jahre) und klinische Daten (einschließlich Schmerzen, Bewegungsumfang, Instabilität) wurden retrospektiv ausgewertet.

Ergebnisse. Im Durchschnitt betrug die Zeit nach dem Trauma 50 (Spanne: 5-360) Monate.
In 38 Fällen wurden Radiuskopffrakturen zunächst für 3,4 (Spanne: 1-8) Wochen mittels Immobilisation behandelt. Eine physiotherapeutische Behandlung wurde in 39 Fällen durchgeführt. In nur der Hälfte der Fälle war eine retrospektive Klassifizierung nach der Mason-Klassifikation möglich: 20 Typ I, 8 Typ II, 5 Typ III und 2 Typ IV. Bei 53 der 70 Patienten lag eine posttraumatische Ellenbogensteife vor, bei 34 eine isolierte laterale und bei 4 Patienten eine isolierte mediale Seitenbandinstabilität. Eine Kombination aus lateraler und medialer Seitenbandinstabilität bestand in 8 Fällen, Ellenbogensteife kombiniert mit einer Instabilität in 27 Fällen. Pro Person waren 1,2 (Spanne: 1-4) chirurgische Eingriffe notwendig. Bei 64 Patienten wurden jeweils eine Arthroskopie (52-mal kombiniert mit einer Arthrolyse) und weitere notwendige
Behandlungen je nach Begleitverletzungen durchgeführt. Der Bewegungsumfang verbesserte sich im Durchschnitt von Flexion/Extension (präoperativ) $131-15-0^{\circ} \mathrm{zu}$ Flexion/Extension (postoperativ) 135-5-0 (Zugewinn: Flexion: 4,2 ${ }^{\circ}$; Extension: $10,6^{\circ}$ ). Schlussfolgerung. Die konservative Behandlung von Radiuskopffrakturen zeigt nicht immer gute Ergebnisse. Gründe hierfür können chronische Instabilitäten, Knorpelschäden, Steife oder eine Kombination davon sein. Eine Verbesserung des Ergebnisses kann über eine arthroskopische Arthrolyse erzielt werden.

Schlüsselwörter

Radiusfrakturen · Ellenbogen · Gelenkinstabilität · Ellenbogensteife · Operation

\section{Ligament instability and elbow stiffness}

In 35 patients (50\%), clinical examination revealed ulnar $(n=3)$, radial $(n=5)$, or bilateral lateral $(n=30)$ ligament instability of the elbow joint (- Fig. 4a). A combination of elbow instability with concomitant posttraumatic elbow stiffness was found in 27 patients (38.6\%).
In all, 53 patients (75.7\%) had symptomatic elbow stiffness with a restricted range of motion (- Fig. 5a, b). Of these patients, $91 \%$ needed arthroscopic arthrolysis including capsulectomy. In addition to the arthroscopic arthrolysis, a total of two open arthrolysis procedures had to be performed. The preoperative range of motion was flexion/extension of $131-15-0^{\circ}$ and pronation/supination of $67-0-71^{\circ}$. At the 6-week follow-up, the range of motion was improved to flexion/extension of $135-5-0^{\circ}$ as well as pronation/supination of $73-0-76^{\circ}$. Extension was improved by $10.6^{\circ}$ and flexion by $4.2^{\circ}$, which corresponds to a total gain in range of motion of $14.8^{\circ}$.

Usually, the arthrolysis treatment was planned for cases of considerable elbow stiffness to improve range of motion and to prepare for a second ulnar or radial ligament reconstruction, if necessary. 

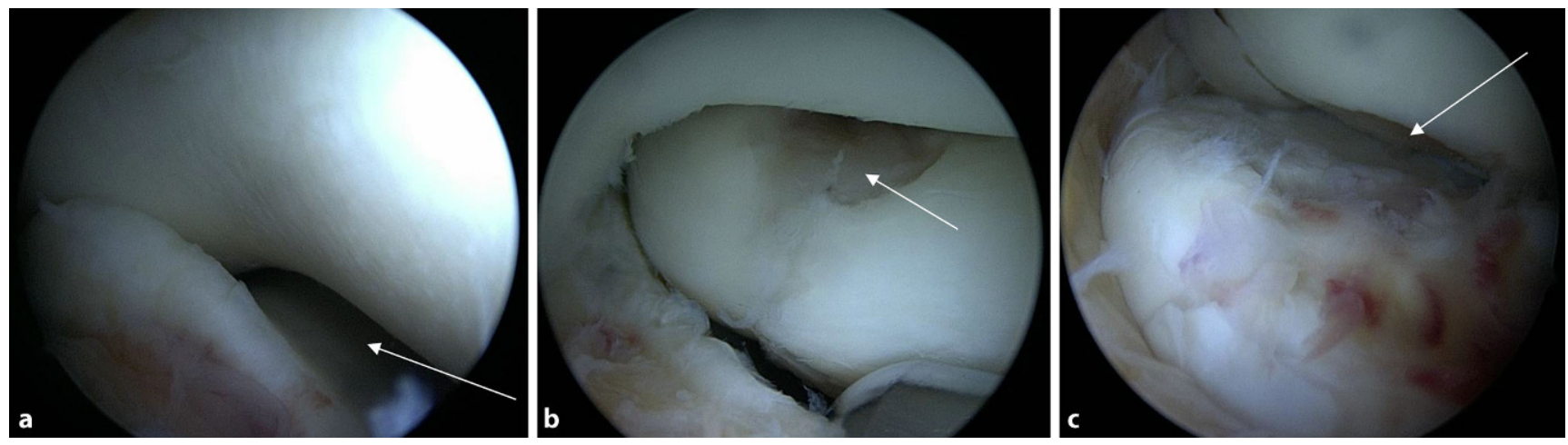

Fig. $4 \Delta$ Gaping joint gap (arrow in a) during arthroscopy and advanced cartilage damage on the radial head and the capitulum humeri (arrows in b, c)
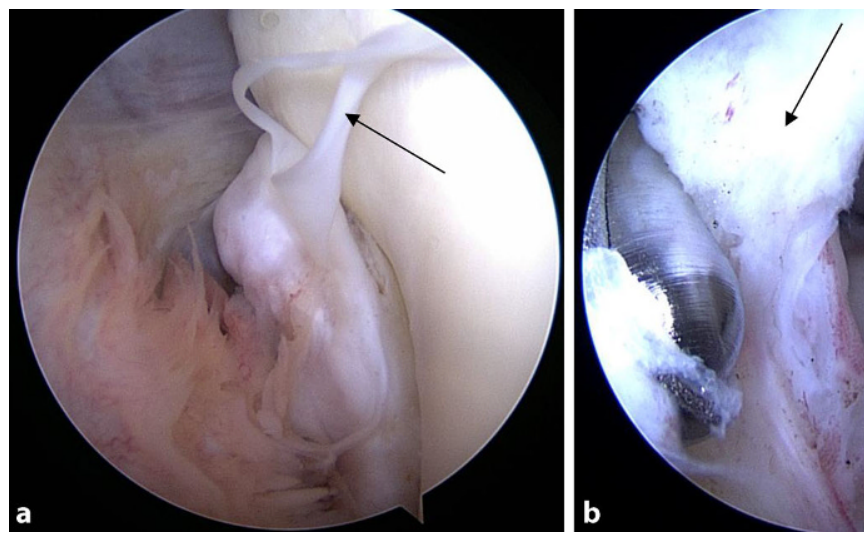

Fig. 5 - Distinct soft-parted bridle strands (arrows)

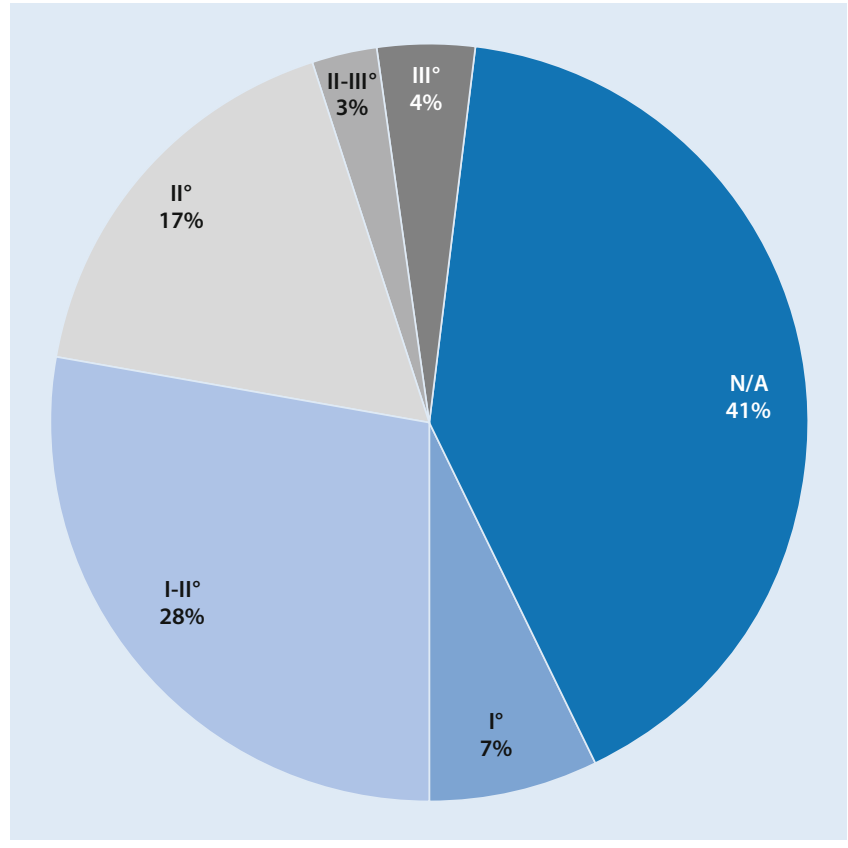

Fig. $6<$ Distribution of posterolateral rotatory instability $(P L R I)$ in the study series: $24 \%$ of the instabilities were graded as PLRI II or greater. N/A no PLRI
Via arthroscopic stability testing with the exchange rod, 18 cases $(25.7 \%)$ of PLRI II or more and 12 cases (17.1\%) of ulnar instability were detected. There was bilateral lateral ligament instability in eight patients (11.4\%). All the other patients had either no PLRI or had lateral instabilities of a grade less than PLRI II; 24 patients exhibited no instability at all (34.3\%).

In five cases $(7.1 \%)$, radial ligament reconstruction had to be carried out in a second surgery (either planned or due to recurrent instability).

Four patients $(5.7 \%)$ required either a radial $(n=2)$ or ulnar $(n=2)$ ligament reconstruction without previous arthroscopy (• Fig. 6). In one case, ulnar ligament reconstruction was performed in a second surgery.

In total, 1.2 surgeries per patient (range, 1-4) were necessary to improve clinical outcome in the 70 patients in our study (57 patients needed only one operation, 12 patients had two operations, and one patient had four operations).

When comparing the findings of clinical and arthroscopic stability testing, we found that 35 patients (50\%) had a medial or lateral ligament instability in the preoperative clinical examination. In $94 \%$ of these cases, the instability was confirmed intraoperatively (25 cases of PLRI, five cases of ulnar instability, and three cases of combined instability). Finally, only 16 patients $(45.7 \%)$ underwent ligament reconstruction:

- In all, 12 cases of lateral ulnar collateral ligament reconstruction (see case report in • Fig. 7): 


\section{Original contribution}
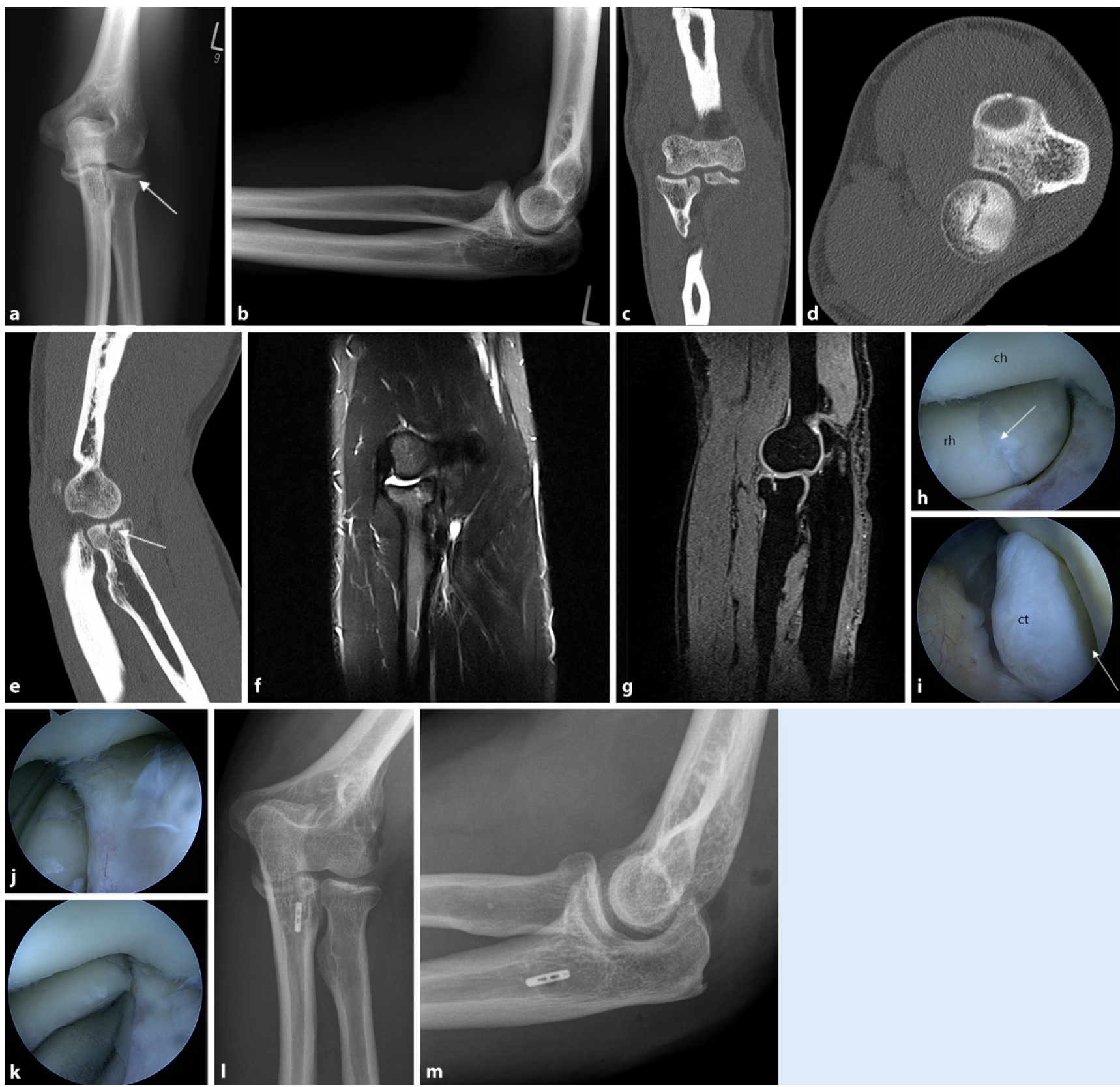

Fig. 7 \& Case report: A 50-year-old patient with a radial head fracture (Mason I) after a fall had persistent symptoms after initial conservative treatment for more than 1 year. Radiography and computed tomography images show no step formation (arrows) at the radial head (a-e). Magnetic resonance imaging confirms the diagnosis of a Mason I fracture, but no soft tissue damage can be detected $(\mathbf{f}, \mathbf{g})$. The intraoperative results 1 year posttrauma show the former fracture $($ arrow) at the radial head $(r h)$ and a gaping humeroradial joint gap (arrow) as an indication of lateral instability (ch capitulum humeri, ct coronoid tip; $\mathbf{h}-\mathbf{k})$. Postoperative radiograph after treatment with lateral ulnar collateral ligament repair $(\mathbf{l}, \mathbf{m})$

- Two cases without arthroscopic treatment

- Five cases in combination with an arthroscopic procedure

- Four cases in a planned second surgery

- One case due to recurrent instability
- Four cases of ulnar reconstruction:

- Two cases without arthroscopic treatment

- Two cases in a planned second surgery

In most cases, however, additional treatment (e.g., neutralizing the instabilities) besides arthroscopic arthrolysis was not necessary (52 cases, $74.3 \%$ ).

The patients with nonstabilized fractures were nevertheless satisfied with the postoperative outcome, so that not all instabilities had clinical relevance in our series. 


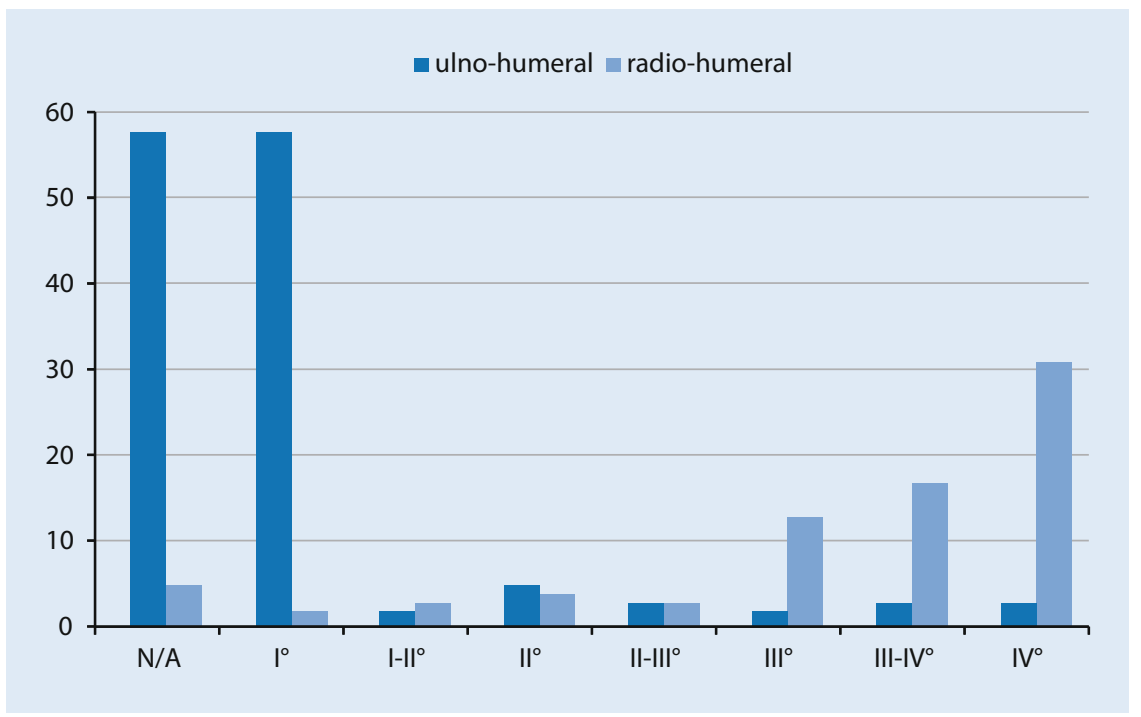

Fig. $8 \Delta$ Cartilage damage according to joint section. A dramatic increase in cartilage damage occurs on the radial side of the elbow joint. $N / A$ no cartilage damages

\section{Cartilage defect}

Depending on the intraoperative findings, accompanying pathologies such as cartilage damage or hypertrophic plicae were addressed in the same surgery.

In only four cases $(5.7 \%)$ were neither humero-ulnar nor humeroradial cartilage defects found. According to the Outerbridge classification [39], the humeroulnar joint itself showed at least grade II or higher cartilage damage in approximately one out of six patients (15.7\%). In the humeroradial joint (radial head and capitulum humeri), $90 \%$ of the patients already had grade II or higher cartilage lesions. Furthermore, $62.5 \%$ of all patients already had at least grade II-III cartilage lesions at the radial head itself, and every third patient (35.7\%) had an advanced grade IV cartilage defect (- Figs. 4b, $c$ and 8).

\section{Reoperation}

In total, 13 patients needed 15 reoperations: two arthroscopic arthrolysis, four open arthrolysis, five lateral ligament reconstructions (one time due to recurrent instability), two ulnar ligament reconstructions, one hinged external fixator, one mobilization under anesthesia. However, nine of these operations were planned second interventions. Six complications were encountered in five patients including recurrent elbow stiffness and one recurrent lateral instability. Therefore, arthroscopic and open revision arthrolysis as well as one revision of a lateral ligament reconstruction had to be performed.

\section{Discussion}

Radial head fractures tend to be underestimated by clinicians, in particular because of the lack of evidence of displacement on plain radiographs and the good results achieved with conservative treatment. However, these injuries may often be accompanied by a high degree of ligamentous and soft tissue as well as intra-articular cartilaginous damage, which cannot be displayed on radiographs [4]. Therefore, a thorough assessment of radial head fractures is necessary in order to determine the true severity and extent of these lesions and to minimize the risk of delayed surgical therapy. The correlation between an osseous lesion of the radial head and ligamentous injuries is well known. Itamura et al. described medial collateral ligament ruptures in 54\%, lateral collateral ligament ruptures in $80 \%$, and bilateral ruptures in $50 \%$ of all cases classified as Mason II and III fractures, while Mason IV fractures were excluded [19].

Hausmann et al. found a partial lesion of the interosseous membrane in nine of 14 patients with Mason I fractures using MRI [16]. Kaas et al. supported these findings, detecting accompanying injuries in Mason I-III fractures including lateral collateral ligament ruptures $(n=28)$ and humeroradial cartilage damage $(n=8)$ in 35 of 46 cases [22-24]. Whether concomitant injuries increase the necessity for surgical treatment remains controversial. Kaas et al. stated that most of the additional lesions in patients with radial head fractures are either not symptomatic or not of clinical importance. However, in their follow-up examination at least 12 months after trauma, flexion and extension deficits occurred in 45 and $43 \%$ of their patients, respectively. In addition, 13 of 40 patients described crepitus and one patient had locking due to a loose body. The authors claimed that no patient needed delayed surgery since symptoms were mild and without major restrictions [23]. In our case series, most of the patients were initially treated elsewhere and did not undergo MRI as they suffered from mainly Mason I and Mason II fractures (28/35 cases).

Conservative treatment for Mason I fractures is regarded the gold standard and yields good to excellent results with temporary immobilization for 5-7 days followed by early functional treatment $[17,43,45]$. However, Burkhart et al. reported on 16 patients with poor outcome after Mason I fractures due to fracture sequelae such as instability, loose bodies, and posttraumatic arthrosis. The trauma mechanism in radial head fractures is similar to that of elbow dislocations. An enhanced clinical and radiological evaluation (typically MRI) is required for type I Mason radial head fractures in order to detect soft tissue and ligamentous damage and to initiate adequate treatment [6]. MRI frequently reveals evidence of elbow dislocation in Mason type I fractures with severe soft tissue injuries. It remains unknown which of these soft tissue injuries might benefit from surgery. However, a study by Adolfsson et al. supports the assumption that the severity of soft tissue injuries correlates with complications. The authors reported on a cohort of patients who experience redislocation despite receiving proper conservative management for a simple elbow 
dislocation. During surgery they found complete avulsions of the medial and/or lateral collateral ligaments and muscle origins [1]. For this reason, the use of MRI to visualize the extent of soft tissue injuries is reasonable. This conclusion is supported by our study. In particular, subjective elbow instability, pre-arthrotic deformities, and restriction in elbow mobility frequently occur after Mason I and II fractures with a negative effect on the clinical outcome. Our approach always includes MRI in selected cases of insufficient clinical improvement during early follow-up even in non-dislocated Mason I fractures. Conservative treatment is aimed for, but concomitant injuries might call for surgery.

In the literature, conservative treatment is still regarded the method of choice for Mason II fractures. In a longterm follow-up study, Akesson et al. reported good to excellent results in about $82 \%$ of cases after conservative management of Mason II fractures. The rate of degenerative changes reached $82 \%$ for the injured and $21 \%$ for the uninjured elbow [2]. Surgical treatment led to similar clinical results ( $82 \%$ good to excellent) 22 years after open reduction and internal fixation (ORIF) in a study by Lindenhovius and colleagues. However, arthrosis was only detected in one of 16 cases in their study [28]. To date, there is no prospective study comparing ORIF with conservative treatment in Mason II fractures. Yoon et al. compared nonsurgical treatment with ORIF in partial articular radial head fractures, but the study was compromised by several biases and the conclusion is therefore limited [44]. The RAMBO trial was initiated in 2014 and aimed to address the question of whether Mason II fractures should be treated conservatively or surgically [5]. Unfortunately, no results from the trial have been published yet. A systematic review by Zwingmann et al. favored ORIF with screws in Mason type II fractures over osteosynthesis with pins or K-wires and over conservative treatment because of better outcomes with the former approach. However, the selection of conservative studies included in the review, dated from 1981 to 1992 , represents a possible bias [46].
Owing to the lower rate of degenerative changes, especially in young patients, we recommend surgery for Mason II fractures. However, the operative approach (screws, plate osteosynthesis, pins etc.) has to be assessed individually.

By contrast, in Mason type III and IV fractures, a surgical approach is the gold standard. The method to be followed, however, is still under discussion since ORIF, as the preferred therapy, and implantation of a radial head prosthesis or radial head replacement represent suitable treatment options $[3,20,25,26,37$, $40,43]$. All these strategies exhibit advantages and disadvantages and are mainly dependent on the expertise of the surgeon.

Our study involved only patients undergoing surgery for fracture sequelae such as instability, restricted range of motion (stiffness), or painful weight-bearing. Elbow stiffness described in the literature, which is significantly correlated with the duration of immobilization, is a serious complication after radial head fractures $[8,29,30,33-35,41,42]$. This was also found in the present study. In most cases, a relevant restriction of elbow movement was one of the main reasons for delayed surgery after initial conservative treatment of non- or only slightly displaced radial head fractures. Regarding the soft tissue damage, some patients with Mason I radial head fractures likely had an injury mechanism similar to an elbow dislocation. Furthermore, the radial head is an important stabilizer against valgus stress in combination with the medial collateral ligament, which was confirmed by several biomechanical studies [12-14, 25, 36].

Soft tissue damage, especially in Mason I fractures, can lead to the classification being adapted after surgical intervention, thereby resulting in a Mason IV fracture.

In contrast to reports in the literature, in which cartilage lesions are described as either asymptomatic or clinically not relevant, our patients suffered remarkably from cartilage damage, which is mostly detected as crepitus during clinical examination. In our series, all complications and all pathologies represented surgical indications due to restricting symptoms.
The difficulty of treating radiocapitellar arthritis especially in young patients is a frequent topic of discussion in the literature. Therefore, prevention of radiocapitellar arthritis seems logical. ORIF of Mason II fractures is a simple procedure with a very high rate of good results and low complication rates.

On the basis of our patient population, we cannot recommend primary surgical treatment for Mason I or Mason II fractures since we did not compare outcomes. Instead, appropriate and extensive diagnostics are necessary to detect concomitant injuries, which might influence the decision on whether the patient will benefit from surgery or not. Furthermore, continuous clinical examinations are highly recommended so as to change conservative treatment when required. We tend to recommend operative therapy for Mason II fractures in cases of concomitant lesions, since degenerative lesions mostly prevailed in our patient group with Mason II fractures.

Thus, measurements that possibly promote complications, such as lengthy immobilization or patients with suspicious injuries who refuse MRI, should be avoided. Although not applicable to all patients and all clinics, we recommend acquiring radiographs in two planes and performing MRI independent of the Masson classification of the fracture. The necessity for surgical treatment has to be evaluated individually in every patient with consideration of age, occupation, sports, and handedness $[4,7,16,19,22$, 23, 32].

Especially the treatment of intraoperatively detected instabilities by means of stabilization surgery (ligament repair or ligament reconstruction) should be assessed individually. In our study, not every arthroscopically detected instability needed surgical stabilization. Even without stabilization, adequate clinical results could be achieved, similar to the findings of Kaas and coworkers [22-24].

The lack of a classification system that combines bony and ligamentous lesions as well as the lack of prospective studies comparing surgical with conservative treatment does not allow for a general therapy algorithm. It is important to pay attention to so-called red flags like re- 
striction of movement, unchanging high pain level, or simply unambiguous elbow instabilities in stress testing a few days after trauma.

\section{Practical conclusion}

- Mason I fractures are associated with soft tissue injuries that might benefit from surgical treatment in select patients. Therefore, we tend to regard radial head fractures as osteoligamentary injuries.

- There is a higher probability of radial head fractures (type Mason II) resulting in posttraumatic osteoarthritis following conservative treatment compared with surgical treatment. Therefore, we recommend surgery to restore anatomy and address soft tissue damage if required.

- Accompanying injuries should be detected at an early stage and treated in a targeted, therapy-adapted manner. Nevertheless, it is still unclear which accompanying injuries are better addressed surgically and which not. In selected cases of insufficient clinical improvement at an early stage of follow-up, MRI should be performed independent of the Mason grade.

- The necessity for surgery must be made according to the MRI findings and the clinical symptoms. Because, independent of Mason grade, only MRI can reveal the full extent of bony and ligamentous injuries. An initially conservative treatment regimen can be changed in favor of an operative procedure in selected cases.

\section{Corresponding address}

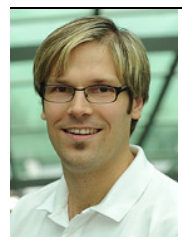

Dr. med. R. Nietschke

Upper Extremity Unit, ARCUS Sportklinik

Rastatter Str. 17-19, 75179 Pforzheim, Germany nietschke@sportklinik.de

\section{Compliance with ethical guidelines}

Conflict of interest. R. Nietschke, K.J. Burkhart, B. Hollinger, F.I. Dehlinger, A. Zimmerer, and M.M. Schneider declare that they have no competing interests.

This article does not contain any studies with human participants or animals performed by any of the authors.

Open Access This article is distributed under the terms of the Creative Commons Attribution 4.0 International License (http://creativecommons.org/licenses/by/ 4.0/), which permits unrestricted use, distribution, and reproduction in any medium, provided you give appropriate credit to the original author(s) and the source, provide a link to the Creative Commons license, and indicate if changes were made.

\section{References}

1. Adolfsson LE, Nestorson NO, Scheer JH (2017) Extensive soft tissue lesions in redislocated after simple elbow dislocations. J Shoulder Elbow Surg 26:1294-1297

2. Akesson T, Herbertsson P, Josefsson PO et al (2006) Primary non-operative treatment of moderately displaced two-part fractures of the radial head. JBone Joint Surg Am 88:1909-1914

3. Beingessner DM, Dunning CE, Gordon KD, Johnson JA, King GJ (2004) The effect of radial head excision and arthroplasty on elbow kinematicsand stability. JBone Joint Surg Am 86-A(8):1730-1739

4. Biberthaler $P$, Bogner $V$, Braunstein V, Wirth S, Mutschler W (2010) Radiuskopffrakturen bei Erwachsenen und Kindern. Trauma Berufskr 12(Suppl2):104-112

5. Bruinsma W et al (2014) A randomized controlled trial of nonoperative treatment versus open reduction and internal fixation for stable, displaced partial articular fractures of the radial head: the RAMBO trial. BMC Musculoskelet Disord 15:147

6. Burkhart KJ, Franke S, Wegmann K, Ries $C$ Dehlinger F, Müller LP, Hollinger B (2014) Mason I fracture-a simple injury? Unfallchirurg 118(1):9-17

7. Chan K, King GJW, Faber KJ (2016) Treatment of complex elbow fracture-dislocations. Curr Rev Musculoskelet Med 9(2):185-189

8. Coulibaly NF, Moustapha NM, Djoumoi HH, Lamine S, Badara GA, Daniel SA (2017) Management of recent elbow dislocations: functional treatment versus immobilization; a prospective study abou 60 cases. Open Orthop J 2017(11):452-459

9. Davidson PA, Moseley JB Jr, Tullos HS (1993) Radial head fracture. A potentially complex injury. Clin Orthop Relat Res 297:224-230

10. Demiroglu $M$, Ozturk K, Baydar M, Kumbulogu OF, Sencan A, Aykut S, Kilic B (2016) Results of screw fixation in Mason type II radial head fracture. Springerplus 5:545

11. Duckworth AD, Watson BS, Will EM et al (2011) Radial head and neck fractures: functional results and predictors of outcome. JTrauma 71:643-648

12. Eygendaal D, Safran MR (2006) Posteromedial elbow problems in the adult athlete. Br J Sports Med 40(5):430-e4

13. Eygendaal $D$, Verdegaal $S H$, Obermann WR, van Vugt AB, Pöll RG, Rozing PM (2000) Posterolatera dislocation of the elbow joint. Relationship to medial instability. J Bone Joint Surg Am 82(4):555-560

14. Fornalski S, Gupta R, Lee TQ (2003) Anatomy and biomechanics of the elbow joint. Tech Hand Up Extrem Surg 7(4):168-178

15. Guzzini $M$, Vadalà $A$, Agrò $A$, Di Sanzo V, Pironi D, Redler A, Serlorenzi P, Proietti L, Civitenga C, Mazza D, Lanzetti RM, Ferretti A (2016) Nonsurgica treatment of Mason type II radial head fractures in athletes. A retrospective study. G Chir 37(5):200-205

16. Hausmann JT, Vekszler $G$, Breitenseher $M$ et al (2009) Mason type-I radial head fractures and interosseous membrane lesions-a prospective study. JTrauma 66:457-461

17. Herbertsson $P$, Josefsson PO, Hasserius $R$ et al (2005) Displaced Mason type I fractures of the radial head and neck in adults: a fifteen-to thirtythree-year follow-up study. J Shoulder Elbow Surg 14:73-77

18. Hollinger B, Franke S (2014) Arthroskopisch gestützte Frakturversorgung am Ellenbogen. Arthroskopie 27:275-282

19. Itamura J, Roidis N, Mirzayan R et al (2005) Radial head fractures: MRI evaluation of associated injuries. JShoulder Elbow Surg 14:421-424

20. Johnson JA, Beingessner DM, Gordon KD, Dunning CE, Stacpoole RA, King GJ (2005) Kinematics and stability of the fractured and implantreconstructed radial head. J Shoulder Elbow Surg 14(1 Suppl S):195S-201S. https://doi.org/10. 1016/j.jse.2004.09.034

21. Josten C, Lill H (2002) Ellenbogenverletzungen. Steinkopff, Darmstadt, pp 1-182

22. Kaas L, Turkenburg JL, Van Riet RP et al (2010) Magnetic resonance imaging findings in 46 elbows with a radial head fracture. Acta Orthop 81:272-276

23. Kaas L, Van Riet RP, Turkenburg JL et al (2011) Magnetic resonance imaging in radial head fractures: most associated injuries are not clinically relevant. J Shoulder Elbow Surg 20:1282-1288

24. Kaas L, Van Riet RP, Vroemen JP et al (2010) The epidemiology of radial head fractures. J Shoulder Elbow Surg 19:520-523

25. King GJ, Zarzour RD, Rath DA, Dunning $C E$, Patterson SD, Johnson JA (1999) Metallic radial head arthroplasty improves valgus stability of the elbow. Clin Orthop Relat Res 268:114-125

26. Kodde IF, Kaas L, Flipsen M, van den Bekerom MP, Eygendaal D (2015) Current concepts in the management of radial head fractures. World $J$ Orthop 6(11):954-960

27. Lill H, Korner J, Rose T, Hepp P, Verheyden P, Josten C (2001) Fracture-dislocations of the elbow joint-strategy for treatment and results. Arch Orthop Trauma Surg 121:31-37

28. Lindenhovius AL, Felsch Q, Ring D et al (2009) The long-term outcome of open reduction and internal fixation of stable displaced isolated partial articular fractures of the radial head. J Trauma 67:143-146

29. Liow RY, Cregan A, Nanda R et al (2002) Early mobilization for minimally displaced radial head fractures is desirable. A prospective randomized study of two protocols. Injury 33:801-806

30. Maripuri SN, Debnath UK, Rao P, Mohatny K (2007) Simple elbow dislocation among adults: a comparative study of two different methods of treatment. Injury 38(11):1254-1258

31. Mason ML (1954) Some observations on fractures of the head of the radius with a review of one hundred cases. BrJ Surg 42:123-132 


\section{Original contribution}

32. McKee MD et al (2003) The pathoanatomy of lateral ligamentous disruption in complex elbow instability. J Shoulder Elbow Surg 12(6):391-396

33. Mehlhoff TL, Noble PC, Benett JB, Tullos HS (1988) Simple dislocation of the elbow in the adult. Results after closed treatment. J Bone Joint Surg Am 70(2):244-249

34. Mellema JJ, Lindenhovius ALC, Jupiter JB (2016) The posttraumatic stiff elbow: an update. Curr Rev Musculoskelet Med 9(2):190-198

35. Mittal R (2017) Posttraumatic stiff elbow. Indian J Orthop 51(1):4-13

36. Morrey BF, Tanaka S, An KN (1991) Valgus stability of the elbow. A definition of primary and secondary constraints. Clin Orthop Relat Res 256:187-195

37. Nestorson J, Josefsson PO, Adolfsson L (2017) A radial head prosthesis appears to be unnecessary in Mason IV fracture dislocation. Acta Orthop 88(3):315-219

38. O'Driscoll SW, Bell DF, Morrey BF (1991) Posterolateral rotatory instability of the elbow. J Bone Joint Surg Am 73(3):440-446

39. Outerbridge RE (1961) The etiology of chondromalacia patellae. J Bone Joint Surg $\mathrm{Br} 43$ B:752-757

40. Pomianowski S, Morrey BF, Neale PG, Park MJ, O'Driscoll SW, An KN (2001) Contribution of monoblock and bipolar radial head prostheses to valgus stability of the elbow. J Bone Joint Surg Am 83-A(12):1829-1834

41. Rafai M, Largab A, Cohen D, Trafeh M (1999) Pure posterior luxation of the elbow in adults: immobilization or early mobilization. A randomized prospective study of 50 cases. Chir Main 18(4):272-278

42. Schippinger G, Seibert FJ, Steinbock J et al (1999) Management of simple elbow dislocations. Does the period of immobilization affect the eventual results? Langenbecks Arch Surg 384(3):294-297

43. Struijs PA, Smit G, Steller EP (2007) Radial head fractures: effectiveness of conservative treatment versus surgical intervention. A systematic review. Arch Orthop Trauma Surg 127:125-130

44. Yoon A, King GJ, Grewal R (2014) Is ORIF superior to nonoperative treatment in isolated displaced partial articular fractures of the radial head? Clin Orthop Relat Res 472(7):2105-2112

45. Weseley MS, Barenfeld PA, Eistenstein AL (1983) Closed treatment of isolated radial head fractures. JTrauma 23:36-39

46. Zwingmann J, Welzel M, Dovi-Akue D, Schmal H, Südkamp NP, Strohm PC (2013) Clinical results after different operative treatment methods of radial head and neck fractures: a systematic review and meta-analysis of clinical outcome. Injury 44(11):1540-1550 